TITLE:

\title{
Investigation of elemental shape for 3D DEM modeling of interaction between soil and a narrow cutting tool
}

AUTHOR(S):

Ono, Ikuya; Nakashima, Hiroshi; Shimizu, Hiroshi; Miyasaka, Juro; Ohdoi, Katsuaki

\section{CITATION:}

Ono, I kuya ... [et al]. Investigation of elemental shape for 3D DEM modeling of interaction between soil and a narrow cutting tool. Journal of Terramechanics 2013, 50(4): 265-276

\section{ISSUE DATE:}

2013-08

URL:

http://hdl.handle.net/2433/179452

\section{RIGHT:}

(C) 2013 ISTVS. Published by Elsevier Ltd.; This is not the published version. Please cite only the published version.; この論文は出版社版で ありません。引用の際には出版社版をご確認ご利用ください。 


\title{
Investigation of Elemental Shape for 3D DEM Modeling of Interaction between Soil and a Narrow Cutting Tool
}

\author{
Ikuya Ono $^{\mathrm{a}}$, Hiroshi Nakashima ${ }^{\mathrm{b}, *}$, Hiroshi Shimizu ${ }^{\mathrm{b}}$, Juro Miyasaka ${ }^{\mathrm{b}}$, \\ Katsuaki Ohdoi ${ }^{\mathrm{b}}$ \\ ${ }^{a}$ Komatsu Ltd., \\ Akasaka 2-3-6, Minato-ku, Tokyo 107-8414 JAPAN \\ ${ }^{b}$ Division of Environmental Science 83 Technology, Graduate School of Agriculture, \\ Kyoto University, Kyoto 606-8502 JAPAN
}

\begin{abstract}
Discrete Element Method (DEM) has been applied in recent studies of soil cutting tool interactions in terramechanics. Actual soil behavior is well known to be inexpressible by simple elemental shapes in DEM, such as circles for $2 \mathrm{D}$ or spheres for $3 \mathrm{D}$ because of the excessive rotation of elements. To develop a more effective model for approximating real soil behavior by DEM, either the introduction of a rolling resistance moment for simple elemental shape or the combination of simple elements to form a complex model soil particle shape cannot be avoided. This study was conducted to investigate the effects of elemental shape on the cutting resistance of soil by a narrow blade using 3D DEM. Six elemental shapes were prepared by combining unit spheres of equal elemental radius. Moreover, cutting resistance was measured in a soil bin filled with air-dried sand to collect comparative data. The elemental shape, with an axial configuration of three equal spheres overlapped with each radius, showed similar results of soil cutting resistance to those obtained experimentally for the six elemental shapes investigated.
\end{abstract}

\footnotetext{
${ }^{*}$ Corresponding author. Tel.: +81-75-753-6164; Fax.: +81-75-753-6165.

Email address: hiron@kais.kyoto-u.ac.jp (Hiroshi Nakashima)
} 
Keywords: DEM, soil cutting resistance, elemental shape, GPU, specific cutting resistance

\section{Introduction}

Interaction between soil and a cutting blade has been a fundamental problem of terramechanics. It is often observed in plow tillage, bulldozing, and excavating work that is conducted with agricultural and construction machines. With a recent trend of customer-oriented design and development of tools for reduced cutting resistance with less fuel consumption, prediction of cutting resistance for soil-engaging tools has become important. Therefore, recent efforts have emphasized the development of CAE systems in soilmachine interaction analysis.

Many previous reports have described computational methods for assessing the interaction between soil and cutting blades. Yong and Hanna[1] applied FEM to soil cutting problems. Although their analysis was based on $2 \mathrm{D}$ formulation, horizontal forces of up to $7.5 \mathrm{~cm}$ of cutting distance were obtainable by introducing joint elements at the assumed cutting depth of the working tool. Chi and Kushwaha [2] applied 3D FEM with a hyperbolic stress-strain model to analyze soil failure under a tillage tool with an interface element. Results showing a failure zone around the tool surface revealed rather limited expansion of failure, mostly activated or exacerbated by the tool itself. Abo-elnor et al. [3] applied a commercially available FEM code, ABAQUS, with a dry sand model based on a hypoplastic constitutive model. In their analysis, a horizontal draft force as well as a vertical force was obtained up to blade displacement of $5 \mathrm{~cm}$. Karmakar et al. [4] applied CFX4.4, a commercial FEM-based CFD code, to simple high-speed tillage tools. They confirmed the increasing distance of a pressure bulb in front of 
tool face up to $4-6 \mathrm{~m} / \mathrm{s}$. However, no information was reported in relation to soil deformation around the tillage tool.

Methods of modeling presented above are categorizable as a continuum modeling approach. Another modeling approach - discrete modeling - has been useful to analyze the interaction between the soil and the cutting blade based on particle dynamics. It is noteworthy that a continuum-based discrete approach named mesh-free FEM, exists, in which traditional finite elements are used no more [5], but the construction of a special shape function is necessary. Moreover, such localized shear lines, which are often observed in terramechanics, are said to be difficult to express, but no other report exists aside from that of Coetzee et al. [6]. They applied the material-point method to the modeling of excavator bucket filling. The most popular analysis in discrete modeling is definitely the discrete element method (DEM).

Shmulevich et al. [7] applied DEM to the analysis of the cutting resistance of soil by a wide blade using PFC2D. The blade cross-section shape was investigated. A straight blade showed the lowest horizontal force during bulldozing, although the vertical force became zero in the case of a parabolic blade. The merit of DEM was demonstrated as easy expression of the instantaneous velocity field around the cutting blade.

A teardrop shape obtained with two clumped spherical elements of different diameter was used in 3D analysis by Coetzee and Els [8]. After determining model parameters through experimental calibration of a simple shear test and a compression test, they compared the cutting of grains by a flat blade with results that were obtained from experiments. The relative displacement was used to construct the position and shape of the shear lines. Results demonstrated that qualitative correlation was obtainable.

Obermayr et al. [9] applied 3D DEM to a quasistatic shear of cohesionless 
soil by a vertical blade. They used a uniform sphere and varied spheres as model soil particles. Moreover, they introduced the idea of retaining particle rotation to avoid excess rotation of spheres in 3D analysis. In spite of their special procedure, which included no rotation of spherical elements, the horizontal draft of simple shear by DEM agreed well with experimentally obtained results and with the theoretical results obtained using the McKeys model.

Recently, Tsuji et al. [10] demonstrated the capability of 3D parallel DEM for both non-cohesive and cohesive soils for the analysis of soil - bulldozerblade interactions. Their vertical blade simulation for non-cohesive soil was performed with a total of 280,000 spherical elements using a 16-core cluster computer system. It is noteworthy that the computation time of one pushing condition was less than $4 \mathrm{~h}$.

The elemental shape is well known to affect the generation of the contact reaction in the analysis of DEM applied to interaction problems [11]. For example, dry Toyoura sand can generate greater cone penetration resistance at higher porosity than that of an artificial material such as alumina balls [12], which implies that the contribution of such factors as particle shape and internal friction angle should be expressed properly in the analysis of interaction for real soils by DEM. Two approaches for expressing particle shapes are a clustering model [11] and a multi-sphere model (MSM) [13]. Because of its simplicity in model construction and applicability, MSM has been popular for expressing complex particle shapes.

Various shapes of model soil by MSM for 3D DEM can be found in the literature. They are classified as the following two types: (a) models consisting of unit spheres with common radii for simple model particles (e.g. clumped element [8]), and (b) models consisting of multiple spheres with different radii 
for more realistic particles (e.g. a model for lunar regolith simulant [14], rice grain model [15]).

For this study, we apply 3D DEM to express large deformation of the soil surface and the lateral flow of soil around the cutting blade, which are often observed in soil - narrow-blade interactions. With the recent development of computer-related technologies, we can use a desktop PC system with a powerful CPU that has large main memory capacity. The final goal of this study is to develop a cost-effective prediction tool for soil cutting resistance in a soil-machine system by DEM on a desktop PC system.

This study is intended to investigate the effect of elemental shape on cutting resistance of soil in the 3D DEM for a soil - narrow-blade system. The elemental shape of DEM becomes important in a virtual soil model that is expressed with larger soil elements instead of using realistic microscale soil particles as an engineering tool. Consequently, model elements of various shapes are prepared with unit spheres with the common radii by following approach (a) reported above. To validate the DEM analysis result, experimental data related to soil cutting were also collected. Then the shape of MSM for DEM was selected by comparison of the experiment results and those obtained through numerical analysis.

\section{DEM for soil - narrow-blade system}

\subsection{Outline of DEM}

For simplicity of modeling at the contact interface of the soil and narrow blade, dry sand is used as the target soil for the initial approach. A linear contact model was used to examine the development of in-house DEM program specifically. In the linear contact model, contact force is calculable as a reaction of a spring that is proportional to an overlap of two elements in 
the case of normal contact of elements. For tangential reactions, the reaction of the tangential spring can be traced by summing up all the tangential displacements from the beginning of contact. Moreover, Coulomb friction is introduced into the calculation of tangential contact reaction. For numerical stability, local damping is added by a damper connected in parallel to the spring in both normal and tangential directions, as presented in Fig. 1.

[Figure 1 about here.]

The motion of each soil element is expressed using the following equations of motion.

$$
\begin{aligned}
& \frac{d \boldsymbol{P}}{d t}=\sum \boldsymbol{F} \\
& \frac{d \boldsymbol{L}}{d t}=\sum \boldsymbol{N}
\end{aligned}
$$

Therein, $\boldsymbol{P}$ stands for the linear momentum, $\boldsymbol{F}$ signifies the force acting on the soil element, $\boldsymbol{L}$ denotes the angular momentum, and $\boldsymbol{N}$ represents the torque acting on the soil element. The explicit numerical solver of Equations (1) and (2) is based on the fourth-order Runge-Kutta method (RK4) in this study. Use of classical RK4 for numerical integration was from its small order of error, although it requires a longer time of computation than other numerical integration methods, such as Modified Euler method and Velocity Verlet.

\subsection{DEM parameters}

[Table 1 about here.]

Parameters for DEM analysis are listed in Table 1 , where $K_{n}$ is the normal spring constant, $K_{t}\left(=0.25 K_{n}\right)$ stands for the tangential spring constant, $\mu$ signifies the coefficient of friction, and $e$ denotes the coefficient of restitution. In the table, $\mathrm{P}-\mathrm{P}$ denotes contact between soil elements, $\mathrm{P}-\mathrm{W}$ signifies 
contact between the soil element and soil bin wall, and $\mathrm{P}-\mathrm{B}$ stands for the contact between the soil element and the cutting blade.

The normal spring constant is decided by referring to the order of data of Tsuji et al. [10] with preliminary computation of the varying normal spring constant. Within the variation of 500, 1000, 2000, 4000, and $8000 \mathrm{~N} / \mathrm{m}$, the normal spring constant was chosen as $2000 \mathrm{~N} / \mathrm{m}$ because the cutting resistance showed no significant difference. The tangential spring constant was set as $K_{t}=0.25 K_{n}$ following the recent examples of DEM analysis [10, 14]. It is noteworthy that the ratio of 0.25 originates from the difference in propagation velocities of $P$-waves and $S$-waves within an isotropic elastic media whose Poisson's ratio is assumed as 0.3 in DEM simulations in earthquake engineering [16].

The coefficient of friction between soil elements $\mu_{P P}$ was based on the result of internal friction angle measured by direct shear testing of actual sand used in the experiments. The friction coefficient between soil elements and the cutting blade $\mu_{P B}$ was based on a measurement of friction using the slope, where the limit slope angle of the steel plate was measured when the object, with its contacting surface glued with sand particles, began to slide on the plate. The coefficient of friction between soil elements and soil bin wall $\mu_{P W}$ was set equal to $\mu_{P P}$ to elucidate the contribution of frictional effects of two soil bin walls in a lateral direction.

The coefficient of restitution $e$ was used for calculation of the normal damping coefficient $\eta$, as in Eq. (3), originally proposed for impact of two elements[17]. The value of $e=0.3$ was based on a result of preliminary computation, where no significant difference was found for two cases of $e=$ 0.0 and $e=0.3$. 


$$
C_{n}=2 \frac{-\ln (e)}{\sqrt{\pi^{2}+\ln ^{2}(e)}} \sqrt{m K_{n}}=2 \eta \sqrt{m K_{n}}
$$

For the tangential damping coefficient $C_{t}$, a factor of $s=K_{t} / K_{n}$ was multiplied to $C_{n}$, such that

$$
C_{t}=\sqrt{s} C_{n}=0.5 C_{n}
$$

The virtual soil bin in DEM is $0.6 \mathrm{~m}$ long, $0.2 \mathrm{~m}$ wide, and $0.4 \mathrm{~m}$ deep. The cutting blade is $150 \mathrm{~mm}$ long, $100 \mathrm{~mm}$ wide, and $9 \mathrm{~mm}$ thick. The cutting velocity of soil is set to $100 \mathrm{~mm} / \mathrm{s}$ in the simulation to reduce the computational load because of the negligible effect of cutting velocity on cutting resistance in the case of target dry sand, which was confirmed by preliminary computations with the velocity condition of $14 \mathrm{~mm} / \mathrm{s}$.

The time step of numerical integration was set to $1.0 \times 10^{-5} \mathrm{~s}$, as determined by the preliminary simulation. The soil cutting in the simulation lasted for $4 \mathrm{~s}$, where the total cutting displacement became $40 \mathrm{~cm}$.

\subsection{Elemental shapes prepared by $M S M$}

Fig. 2 shows six shapes of DEM elements, S1, L2, L3, C8, M7, and T4, designed. Model S1 is a simple sphere model as a reference, whereas model L2 consists of two spheres connected axially as in a clumped element. Model L3 comprises three spheres connected axially. Model C8 includes eight spheres of which the locations are on cubic vertices. Model M7 has a combination of seven spheres, six of which are on a positive and negative 3D Cartesian coordinate system with a common radius and one is at the origin of the coordinate system. Model T4 uses four spheres, each of which is at a vertex of a regular tetrahedron. In all MSM models shown in Fig. 2, the overlap length of spheres is equal to the composing sphere radius. 
[Figure 2 about here.]

[Table 2 about here.]

Table 2 presents a summary of the total number of particles NE used in soil cutting simulation, where PN signifies the number of particles per MSM element and NE1 is the total number of MSM elements. Moreover, the diameter of elemental particles is generated randomly element-by-element among 4, 5, and $6 \mathrm{~mm}$ with a mixture ratio of 1:1:1, along with random orientation of MSM elements in the initial data generation.

In the current analysis, the mass and moment of inertia tensor for each MSM model are calculated numerically beforehand by dividing the shape of MSM model into small unit cubes of which the side lengths are 1/100 of the radius of unit sphere.

\subsection{Definition of the blade interface}

The introduction of MSM increases the computational time. Therefore, possible methods for reduction of computational load in the 3D DEM should be introduced into the analysis.

The cutting blade was modeled using a signed distance function [18]. In this modeling, the three-dimensional blade surface is divided into $2 \mathrm{D}$ triangle elements, as in FEM. Then the surrounding 3D space near the blade is divided regularly into computational grids, or mesh, of a fixed unit of length. For each grid point, the distance to the surface, or to the edge or to the node, of the triangle element on the cutting blade is calculated and prepared as though it might be regarded as a function of distance data to the cutting blade. The contact between the soil element and blade element is then detected using the coordinate of the soil element and the distance function at the same coordinate interpolated linearly from grid points of a mesh to which 
the soil element belongs. The soil element of interest can be judged as being in contact with the blade if the sign of the distance becomes negative.

The preprocessing time of preparation for generating the distance function depends on the unit length size, the space grid, and the blade target shape. For unit length of $3 \mathrm{~mm}$ with plane cutting blade, as in this study, about 5.8 s were necessary to generate a distance function of a cutting blade.

\subsection{Acceleration with GPU}

In terms of computer hardware, if we use the combined environment of $\mathrm{CPU}$ and the graphic processing unit (GPU), then faster processing can be expected in DEM simulations, even for a large-scale problem [18].

In our study, all computations of generation element shape, distance function, and main DEM analysis were conducted on a desktop PC, of which the CPU was an Intel Core i7 990X with $3.46 \mathrm{GHz}$, with main memory of 24 GByte and a Cent Linux operating system. The GPU installed in the PC (Tesla C2075; Nvidia Corp.) had on-board memory of 6 GByte. The program code was written in $\mathrm{C}++$ and compiled in Nvidia's CUDA environment.

Special tuning of the code developed for the GPU environment has not yet been implemented sufficiently, but the coordinate data are copied initially from the CPU to GPU. The main DEM simulation is executed on GPU. For post-processing purposes, in every event of the time step for data output, coordinate data of DEM elements and soil reaction on a cutting blade are copied to the global memory of GPU to prepare for saving of result files when the DEM computation in GPU is finished. Figure 3 portrays a schematic program flow of DEM in the GPU environment. In the figure, the process with symbol $\mathrm{H}$ shows a process on the host CPU. The position of soil elements was copied with the frequency of $10 \mathrm{~Hz}$ and soil resistance with the frequency of $500 \mathrm{~Hz}$ for post-processing purposes. 
[Figure 3 about here.]

\section{Experiments}

Experiments were conducted in a soil bin, as shown in Fig. 4, which was designed originally for a tire traction measurement system [19]. Total quantities of experiments were 33, with 11 different combinations of the cutting angle and cutting depth, and three times the repetition for each combination of experimental conditions. In this study, the cutting angle is the angle between the horizontal axis and the cutting blade surface.

[Table 3 about here.]

Table 3 presents a summary of the combination of experimental conditions. The cutting depth was classified into three groups beforehand. Then the precise depth was measured every time in each experiment [20].

To obtain uniform soil conditions, soil was mixed and compacted before each experiment using a mixing and compaction device (MCD) [19], as shown in Figs. 5 and 6 . The soil surface became flat under the compacting roller, but at the end of soil, the slope where the blade would start to cut the soil was formed with slight variation of the shape of the sloped surface depending on the mixed soil quantity. The effective soil bin size is $3015 \mathrm{~mm}$ long, 480 $\mathrm{mm}$ wide, and $605 \mathrm{~mm}$ deep. The soil bin was filled with air-dried sand for water filtration, of which the average particle diameter was $0.6 \mathrm{~mm}$.

The dimensions of the cutting blade in the experiment are the same as in the numerical analysis. The cutting velocity in experiments was set to 14 $\mathrm{mm} / \mathrm{s}$. Moreover, the case of cutting velocity of $100 \mathrm{~mm} / \mathrm{s}$ was observed in the preliminary experiments, and the stationary cutting resistance of sand showed similar results to those obtained in the case of $14 \mathrm{~mm} / \mathrm{s}$, although the initial stage exhibited a sudden rise in the cutting resistance curve. 
Both horizontal and vertical cutting resistance were measured using an extended octagonal ring transducer mounted at the frame of the cutting blade. The cutting displacement was monitored using a wire-type displacement sensor (DTP-D-2KS; Kyowa). The entry angle of the tool blade to the soil surface was not kept constant because the soil slope shape was not controlled in the experiment. Therefore, the average cutting resistance was compared using 300 data obtained with cutting displacement of $400 \mathrm{~mm}$.

[Figure 4 about here.]

[Figure 5 about here.]

[Figure 6 about here.]

\section{Results and discussion}

\subsection{Experimental results}

Among the results of 33 experiments, the case for cutting angle of $45 \mathrm{deg}$ and cutting depth of $61.5 \mathrm{~mm}$ is used to compare the effect of the elemental shape on the soil cutting resistance.

Fig. 7 presents an example of the experimentally obtained result for the selected condition. As the figure shows, horizontal soil cutting resistance first increases drastically during the cutting displacement of up to $150 \mathrm{~mm}$. It then tends to settle to a constant resistance of about $22 \mathrm{~N}$ after $300 \mathrm{~mm}$ of displacement. Similar behavior of curves is visible in the case of vertical soil cutting resistance in the figure.

[Figure 7 about here.] 


\subsection{Effects of elemental shape on the cutting resistance}

Figs. 8 and 9 present all results of horizontal and vertical soil resistance for six elemental shapes of MSM investigated using the result of a cutting angle of $45 \mathrm{deg}$ and cutting depth of $61.5 \mathrm{~mm}$. For reference, experimentally obtained results are also depicted in these figures.

[Figure 8 about here.]

[Figure 9 about here.]

The sphere element S1 clearly shows low horizontal soil reaction, although a comparable result of soil reaction can be obtained using element L3. Rolling friction is not implemented in the current analysis. Therefore, low cutting resistance in the case of the $\mathrm{S} 1$ shape is an expected result. Moreover, other shapes of MSM elements show larger horizontal soil resistance that is comparable to the result of experiments.

To compare the effect of model shapes on soil cutting resistance more decisively, the average cutting resistances for both horizontal and vertical components were calculated using the last 300 data of cutting resistance, which correspond to the last section of displacement of $60 \mathrm{~mm}$.

The result of average cutting resistance is depicted in Fig. 10.

[Figure 10 about here.]

As the figure shows, the results of 3D DEM using MSM more closely approaches the experimental average cutting resistance for horizontal and vertical components than those of the conventional sphere model S1. Among the tested elemental shapes of MSM, the result of the L3 model comes nearest to those of experiments.

[Table 4 about here.] 
To find the source of difference in horizontal and vertical components of soil cutting resistance, the normal and tangential cutting resistances are obtained by coordinate transformation as in Table 4, with the resultant $R=\sqrt{F_{n}^{2}+F_{t}^{2}}$ and friction coefficient $\mu_{f}\left(=F_{t} / F_{n}\right)$ between the cutting blade and soil model, using the cutting angle of the narrow blade. In the table, normal cutting resistance $F_{n}$ becomes positive when it directs outward normal of acting cutting blade, whereas tangential cutting resistance $F_{t}$ is positive when $F_{t}$ points downward over the cutting blade.

From the table, two models of L3 and M7 yield similar values of results. The case of L3 shows results that more closely match the experimentally obtained result. Other models, such as L2, C8, T4, and S1, exhibit smaller results. Moreover, the L3 model shows a similar friction angle to that of the experimentally obtained result, but the M7 model exhibits a larger friction angle than the L3 model does. As for other models, the C8 model also generates a larger friction angle than the L3 model, but the friction angle of the T4 model becomes similar to that of the L3 model. It is noteworthy that the friction angle of the S1 model shows a similar value to that of the input friction coefficient $\mu_{P B}=0.3$. The friction coefficient $\mu_{P B}$ was obtained based on the slope method, as shown in 2.2. Therefore, the real mechanism of surface friction between soil elements and the cutting blade might be different in the experiments and in such MSM models as L3, M7, L2, C8 and T4.

[Figure 11 about here.]

The result of DEM obtained using model L3 for a 90 deg cutting angle and cutting depth of $63.2 \mathrm{~mm}$ is presented in Fig. 11 to demonstrate the applicability of DEM using common DEM parameters for different cutting conditions. The figure shows clearly that DEM with model L3 can simulate 
the experimentally obtained result of the cutting angle of 90 deg when the same DEM parameters of L3 are input in the case of a cutting angle of 45 deg.

\subsection{Empirical soil cutting relations}

Comparison of all results of experiments and those of DEM are attempted in terms of the empirical formula for cutting resistance proposed by Hata [21]. All 33 results of experiments on Table 3 are used along with corresponding results of 3D DEM with the L3 element.

A steady-state horizontal cutting resistance of a blade can be expressed as the following empirical relation[21],

$$
F_{H}^{\alpha}=1.8 R_{s} B D^{2} 10^{-0.45 \alpha}
$$

where $F_{H}^{\alpha}$ signifies the horizontal cutting resistance, $R_{s}$ stands for the specific cutting resistance, which becomes constant for a uniform sandy soil, $B$ denotes the blade width, $D$ represents the cutting depth, and $\alpha$ is the rake angle of blade expressed as $\alpha=90^{\circ}-\beta\left(^{\circ}\right)$.

From Eq. (5), $F_{H}^{\alpha}$ might be expressed in proportion to the following term because $R_{s}$ and $B$ are constants.

$$
F_{H}^{\alpha} \propto D^{2} 10^{-0.45 \alpha}
$$

Moreover, using the geometrical relation of the rake angle $\alpha$ of the blade and friction angle $\delta$ over horizontal cutting resistance, steady vertical cutting resistance can be expressed as

$$
F_{V}^{\alpha}=F_{H}^{\alpha} \tan (\delta-\alpha)
$$

where $F_{V}^{\alpha}$ denotes the vertical cutting resistance and $\delta$ represents the friction angle between the blade and soil. 
Therefore, substituting Eq. (6) into $F_{H}^{\alpha}$ of Eq. (7), $F_{V}^{\alpha}$ is also expressed as linear with respect to $D^{2} 10^{-0.45 \alpha} \tan (\delta-\alpha)$ as

$$
F_{V}^{\alpha} \propto D^{2} 10^{-0.45 \alpha} \tan (\delta-\alpha)
$$

Based on Eqs. (6) and (8) presented above, both results of experiments and simulations are depicted, respectively, in Figs. 12 and 13.

All the experimentally obtained results for horizontal soil resistance in Fig. 12 are understood to have a linear relation, as expected from Eq. (6). Moreover, the result of DEM shows a similar linear relation to that of the experiment results. It is noteworthy that some of the experimentally obtained results show scattering because the result of cutting distance of $400 \mathrm{~mm}$ was used for the experimentally obtained results and because the stationary cutting resistance is not yet obtained at this distance of $400 \mathrm{~mm}$. Although it is not shown here, the experimentally obtained result obtained using stationary soil cutting resistance at $1200 \mathrm{~mm}$ shows a clearer linear relation without significant deviation of the data [23], as in the figure.

[Figure 12 about here.]

Moreover, the experimental vertical soil resistance in Fig. 13 comes to lie on a line, as expected from Eq. (8), although variation exists in some cases of experimentally obtained results for the same reason as that stated above for the horizontal cutting resistance.

[Figure 13 about here.]

Based on the results presented in Figs. 12 and 13, it is apparent that 3D DEM using the L3 element is applicable to the soil-blade system, and the soil model L3 can explain the result of the empirical relation with sufficient accuracy. 


\subsection{Model soil deformation in L3 and MY}

Examples of soil deformation are shown respectively in Figs. 14 (side view), 15 (top view) and 16 (front view) for model L3, and in Figs. 17 (side view), 18 (top view) and 19 (front view) for model M7, respectively.

[Figure 14 about here.]

[Figure 15 about here.]

[Figure 16 about here.]

[Figure 17 about here.]

[Figure 18 about here.]

[Figure 19 about here.]

Soil elements in front of cutting blade in Fig. 14 clearly rise to a stable form where the surplus elements flow out at both side edges of the cutting blade, which correlates well with experimental soil behavior, as shown in Fig. 4. Figure 14 also shows the overflow of soil elements at the top edge of cutting blade, which is often observed for larger levels of cutting depth in experiments. The top view in Fig. 15 also demonstrates an arc-like shape of soil boundary on the surface of cutting blade. The soil elements from deeper parts of the soil layer slide up over the cutting blade. Fig. 16 depicts the front view of soil upheaval, which resembles a sand pile. It is noteworthy that the average angle of repose measured using the slope angles along both left and right slopes becomes about $30 \mathrm{deg}$, which is similar to the internal friction angle of sand of $29.2 \mathrm{deg}$ measured using the plane shear test.

As for the M7 model, characteristics stated above for the L3 model are also apparent in Figs. 17-19. Furthermore, it is noteworthy that the soil 
height for an M7 model in the soil bin became higher than that for L3 model because of the larger number of particles $(\mathrm{NE}=156016)$ in the M7 model (see Table 2).

\subsection{Elapsed time of 3D DEM computation for L3 and $M^{7}$ models}

[Figure 20 about here.]

Fig. 20 shows the elapsed time of 3D DEM using L3 and M7 models by GPU. For reference, the time of DEM only by CPU using L3 model is also shown in the figure.

It is clear that the use of GPU contributes to the reduction of computational time in 3D DEM. The elapsed time for CPU-only computation was 829,823 s. Therefore, the acceleration ratio can be calculated as 5.5 $(=829823 / 151824)$ for the L3 model. If further tuning of program such as efficient use of GPU memories is applied, then this ratio can be improved.

The elapsed time for the case of L3 was 151,824 s, whereas that of M7 was 156,532 s. Considering the differences in all number of particles NE in the two models of L3 and M7, the difference in the elapsed time is regarded as not so large. This result can be explained as follows: The particle located at the origin of the model is negligible for contact reaction calculation in M7 model; because the mass of M7 model is more than two times greater than that of L3 model, the relative displacement of neighbor element per given time step is not so large, which results in the effective contact search in the simulation.

Additionally, the real time factor is calculable by the ratio of elapsed time of computation to the real physical time in experiments, and by definition it will become 1 for an ideal real time simulation. For example, Tsuji et al. [10] performed $6 \mathrm{~s}$ of soil cutting simulation by domain decomposition 
method with the MPI library using a parallel processing computer system with a maximum of $4 \mathrm{~h}$, or $14400 \mathrm{~s}$, which caused 2400. This factor explains their better performance as a computing environment. They used a bond force model of Utili and Nova [22] with simple sphere elements of 280,000.

In our case, the real time factor becomes $151824 \mathrm{~s} / 4 \mathrm{~s}=37,956$ for the L3 model, and $156532 \mathrm{~s} / 4 \mathrm{~s}=39,133$ for the M7 model. It is noteworthy that no introduction of domain decomposition method but simple use of GPU was applied on the desktop PC used in this study.

\subsection{Simulation of cutting resistance with controlled porosity}

The strength of dry sand depends on the void ratio or porosity. A comparison of elemental shapes in Fig. 10 reveals that the initial porosity condition of model soil might not be the same in the L3 model and M7 model. To observe the effect of the model shape more precisely, a numerical simulation using the same initial porosity was attempted for L3 and M7 models.

First, the possible range of initial porosity was investigated numerically by changing the friction coefficient from 0.0 to 1.0 for the initial consolidation stage of DEM among L3, M7, and S1 models. The result is shown in Fig. 21.

[Figure 21 about here.]

As the figure shows, it is noteworthy that the sphere model (S1) shows a smaller range of variation on porosity than other models of L3 and M7. The figure also shows that the porosity condition of M7 model is always higher than that of L3 model when the same friction coefficient is used for initial soil model preparation in the program. Consequently, it might be said that the M7 model has a larger friction effect between model particles, which prevents easier dislocation of contacting particles. Moreover, the dry sand used in the 
experiments was confirmed to have a porosity range of 0.389 to 0.453 by the impact hammer method of soil preparation [23].

Therefore, the target porosity condition was designed as shown in Table 5 by changing the initial friction coefficient based on the distribution in Fig. 21.

[Table 5 about here.]

For the S1 model, larger porosity cannot be realized by the adjustment of the friction coefficient. It is therefore marked as NA in the table.

The result of cutting resistance for the porosity of 0.453 is shown in Fig. 22. The model soil is loosely compacted. Therefore, the results obtained using L3 and M7 also show smaller values of cutting resistance.

[Figure 22 about here.]

[Figure 23 about here.]

[Figure 24 about here.]

Figs. 23 and 24 respectively present results of cutting resistance for the porosity conditions of 0.408 and 0.389 . Although the porosity differs in these two figures, the cutting resistance for the L3 model reaches $25 \mathrm{~N}$ for horizontal resistance and -12 N for vertical resistance. Similar behavior of soil resistance is apparent in model M7. No significant difference was found in the case of model S1 in Figs. 23 and 24.

Tables 6-8 list average normal and tangential cutting resistance, resultant and friction coefficient obtained using the last 300 data of horizontal and vertical cutting resistance for each condition of controlled porosity.

[Table 6 about here.] 
[Table 7 about here.]

[Table 8 about here.]

These tables show that the difference of results between those of L3 and M7 models is small for the porosity condition of 0.453 , but that it becomes greater along with the decrease in porosity. As for tangential cutting resistance, the results obtained for the L3 model in Table 6 are between 7.77 and $11.95 \mathrm{~N}$. However, the result of M7 model in Table 7 varies 8.94 to $18.36 \mathrm{~N}$. Results show that the obtained friction coefficient $\mu_{f}$ for the M7 model becomes larger than that for L3 model. The result obtained using the S1 model, on the other hand, shows rather similar values of result, slightly varied friction coefficient, as shown in Table 8.

Judging from the soil cutting resistances in Figs. 22 and 23, the porosity condition in experiments should lie between 0.408 and 0.453 .

\subsection{Overall discussion of L3 and M7 models}

Fig. 10 shows that the L3 model can simulate the experimental cutting resistance of soil by a narrow blade with sufficient accuracy. As a rough approximation, similar results of average horizontal cutting resistance comparable to experimentally obtained results can be obtained using L3 and M7 models. However, the obtained friction coefficient for models L3 and M7 are slightly different. The friction coefficient of L3 model becomes more nearly equal to that of experimentally obtained result, as shown in Table 4.

As for soil deformation shown in Figs. 14-16 for model L3, and in Figs. 17-19 for model M7, no significant difference of deformations between two models was observed.

In the controlled porosity condition, two models of L3 and M7 show no significant difference of cutting resistance for porosity of 0.453 . For smaller 
porosity conditions of 0.389 and 0.408 , the average horizontal resistance of M7 model became greater than that of the L3 model. The experimental porosity condition is estimated as lying between 0.408 and 0.453 . Therefore, it is clear that the difference of the L3 model and the M7 model is not significant for the average cutting resistance, as shown in Fig. 10.

From the geometrical viewpoint of elemental shape, the L3 shape has the aspect ratio $(c / a)$ of 0.5 when it is assumed as an ellipsoid, expressed as $x^{2} / a^{2}+y^{2} / b^{2}+z^{2} / c^{2}=1$, because the longer axis is $a=2 \times r$ and the vertical axis to longer axis is $c=r$. Reportedly, Toyoura sand, which is widely used for soil mechanics studies in Japan and which has smaller average particle diameter of $0.26 \mathrm{~mm}$ than the sand in this study of $0.6 \mathrm{~mm}$, can be modeled as an ellipsoid which has a similar largest distribution of aspect ratio around 0.50-0.55 [24]. Therefore, in terms of the aspect ratio, the shape of current L3 model is similar to an ellipsoid model of Toyoura sand, although the other ratios on elongation, $b / a=0.5$, and flatness, $c / b=1.0$, differ from those of the Toyoura sand model.

It is said that such a bar-like shape of element as in L3 model has characteristics of biased orientation, where its longer axis tends to lie horizontally when the elements are consolidated, whereas the shape of M7 model will be easily piled up without exhibiting strong dependence of orientation. However, Figs. 14-16 show that such an orientation problem might be negligible in the current L3 model. The L3 model has a similar aspect ratio to that of Toyoura sand. Therefore, it is expected that similar results of soil deformation can be obtained if the particle diameter could be reduced to the particle size of real sand. Such an ellipsoid soil model with smaller particle diameter than the current L3 model with the same physical quantities of aspect ratio, elongation ratio, and flatness ratio to the real sand should be introduced to 
simulate cutting resistance of dry sand more precisely.

In the case of the M7 model, it is difficult to rationalize a shape effect in terms of particle geometry in relation with the real particle having the shape of sand. It is interesting to see the result of similar large friction coefficient $\mu_{f}$ as in Table 4 for models M7 and C8, which have shapes that are thought to be effective for emphasizing the rolling friction moment of the element. Results of decreased porosity conditions show an increase of the friction coefficient $\mu_{f}$ in model M7 in Table 7 . The effect of elemental shape on friction coefficients $\mu_{P B}$ and $\mu_{P P}$ under different porosity conditions should be investigated.

Finally, for effective model preparation, a shape model consisting of fewer particles and having similar behavior to that of real soil particles is recommended in 3D DEM. Therefore, model L3 is inferred to have a shape that can simulate the experimental cutting resistance of soil by a narrow blade with sufficient accuracy.

\section{Concluding remarks}

Soil cutting of dry sand by a narrow blade was analyzed using 3D DEM with multi-sphere models of soil elements. Among the shapes of the multisphere models that were investigated, model L3 with axial configuration of three equal spheres overlapped with each radius showed similar results of soil cutting resistance. They were comparable to those of the experimentally obtained result.

\section{Acknowledgments}

Experiments in this study were supported in part as joint research with Caterpillar Japan Inc. during 2010-2012. Moreover, the development of 3D DEM code for use in GPU was a part of Research Project No. 23580359, 
conducted under a Grant-in-Aid for Scientific Research (C) from the Japan Society for the Promotion of Science.

\section{References}

[1] Yong RN, Hanna AW. Finite element analysis of plane soil cutting. J Terramechanics 1997;14(3):103-125.

[2] Chi L, Kushwaha RL. A non-linear 3-D finite element analysis of soil failure with tillage tools. J Terramechanics 1990;27(4):343-366.

[3] Abo-Elnor M, Hamilton R, Boyle JT. Simulation of soil-blade interaction for sandy soil using advanced 3D finite element analysis. Soil and Tillage Research 2004;75(1):61-73.

[4] Karmakar S, Kushwaha RL, Lague C. Numerical modeling of soil stress and pressure distribution on a flat tillage tool using computational fluid dynamics. Biosystems Engineering 2007;97(3):407-414.

[5] Liu GR. Mesh free methods. Boca Raton: CRC Press LLC, 2002.

[6] Coetzee CJ, Basson AH, Vermeer PA. Discrete and continuum modelling of excavator bucket filling. J Terramechanics 2007; 44: 177-186.

[7] Shmulevich I, Asaf Z, Rubinstein D. Interaction between soil and a wide cutting blade using the discrete element method. Soil and Tillage Research 2007;97(1):37-50.

[8] Coetzee CJ, Els DNJ. Calibration of granular material parameters for DEM modelling and numerical verification by blade-granular material interaction. J Terramechanics 2009;46:15-26. 
[9] Obermayr M, Dressler K, Vrettos C, Eberhard P. Prediction of draft forces in cohesionless soil with the Discrete Element Method, J Terramechanics 2011;48:347-358.

[10] Tsuji T, Nakagawa Y, Matsumoto N, Kadono Y, Takayama T, Tanaka T. 3-D DEM simulation of cohesive soil-pushing behavior by bulldozer blade. J Terramechanics 2012;49(1):37-47.

[11] Jensen RP, Bosscher PJ, Plesha ME, Edil TB. DEM simulation of granular media structure interface: effects of surface roughness and particle shape. Int J Numer Anal Meth Geomech 1999;23:531-547.

[12] Nakashima H, Toki Y. Attempt of accurate modeling for cone penetration resistance obtained from particulate media. In: Proc. Powders \& Grains 2009, Golden, 421-424.

[13] Favier JF, Abbaspour-Fard MH, Kremmer M. Modeling nonspherical particles using multisphere discrete elements. Journal of Engineering Mechanics 2001;127(10):971-977.

[14] Matsushima T, Katagiri J, Uesugi K, Tsuchiyama A, Nakano T. 3D shape characterization and image-based DEM simulation of the lunar soil simulate FJS-1. Journal of Aerospace Engineering 2009;22(1):1523.

[15] Markauskas D, Kacianauskas R. Investigation of rice grain flow by multi-sphere particle model with rolling resistance. Granular Matter 2011;13:143-148.

[16] Hakuno M. Simulation of rupture-tracing rupture by an extended discrete element method. Tokyo: Morikita Publishing Co., Ltd., 1997. 
[17] Babic M, Shen HH, Shen HT. The stress tensor in granular shear flows of uniform, deformable disks at high solid concentrations. J Fluid Mechanics 1990;219:81-118.

[18] Harada T, Tanaka M, Koshizuka S, Kawaguchi Y. Acceleration of distinct element method using graphics hardware. Trans. JSCES 2007, Paper No. 20070011, 1-9. (in Japanese)

[19] Shinone H, Nakashima H, Takatsu Y, Kasetani T, Matsukawa H, Shimizu H, Miyasaka J, Ohdoi K. Experimental analysis of tread pattern effects on tire tractive performance on sand using an indoor traction measurement system with forced-slip mechanism. Engineering in Agriculture, Environmental and Food 2010;3(2):61-66.

[20] Ono I. Attempt to measure soil cutting force precisely in soil-machine system. Unpublished Bachelor of Agricultural Sciences Thesis, Department of Agricultural and Environmental Engineering, Faculty of Agriculture, Kyoto University, Kyoto, 2011. (in Japanese)

[21] Hata S. Construction Machinery. Tokyo: Kajima Institute Publishing Co., Ltd., 1987. (in Japanese)

[22] Utili S, Nova R. DEM analysis of bonded granular geomaterials. Int J Numer Anal Methods 2008; 32: 1997-2031.

[23] Ono I. Analysis of dry sand cutting by a narrow blade using particlebased numerical methods. Unpublished Master of Agricultural Sciences Thesis, Division of Environmental Science \& Technology, Graduate School of Agriculture, Kyoto University, Kyoto, 2013. (in Japanese)

[24] Matsushima T, Uesugi K, Nakano T, Tsuchiyama A. Microstructural 
quantification of granular assembly studied by micro x-ray CT at SPring-

8. Journal of Applied Mechanics, JSCE 2008;11:507-511. 


\section{List of Figures}

1 Contact model. . . . . . . . . . . . . . . . . . . . . . . 29

2 Elemental shapes in DEM. . . . . . . . . . . . . . . . 30

3 Schematic flow of DEM in GPU computation. . . . . . . . . . 31

4 Photograph of a soil-cutting experiment. . . . . . . . . . . 32

$5 \quad$ Soil mixing process using the electric rotary tiller in MCD. . . 33

$6 \quad$ Soil compaction using a powered roller in MCD. . . . . . . . . 34

$7 \quad$ Example of an experimentally obtained results. . . . . . . . . 35

8 Horizontal cutting resistance using MSM. . . . . . . . . . . . 36

9 Vertical cutting resistance using MSM. . . . . . . . . . . . . 37

10 Comparison of average cutting resistance. . . . . . . . . . . 38

11 Case of $90 \mathrm{deg}$ cutting angle. . . . . . . . . . . . . . 39

12 Horizontal soil resistance. . . . . . . . . . . . . . . . . 40

13 Vertical soil resistance. . . . . . . . . . . . . . . . 41

14 Side view of soil behaviors in L3. . . . . . . . . . . . . . . . 42

15 Top view of soil behaviors in L3. . . . . . . . . . . . . . 43

16 Front view of soil behaviors in L3. . . . . . . . . . . . . . . 44

17 Side view of soil behaviors in M7. . . . . . . . . . . . . . . . 45

18 Top view of soil behaviors in M7. . . . . . . . . . . . 46

19 Front view of soil behaviors in M7. . . . . . . . . . . . . 47

20 Elapsed time of 3D DEM using L3 and M7 models. . . . . . . 48

21 Possible porosity condition in DEM. . . . . . . . . . . . . . . 49

22 Case of porosity condition of $0.453(\mathrm{H} 0) \ldots \ldots \ldots$. . . . . . 50

23 Case of porosity condition of 0.408 (H25). . . . . . . . . 51

24 Case of porosity condition of $0.389(\mathrm{H} 250)$. . . . . . . . . . . 52 


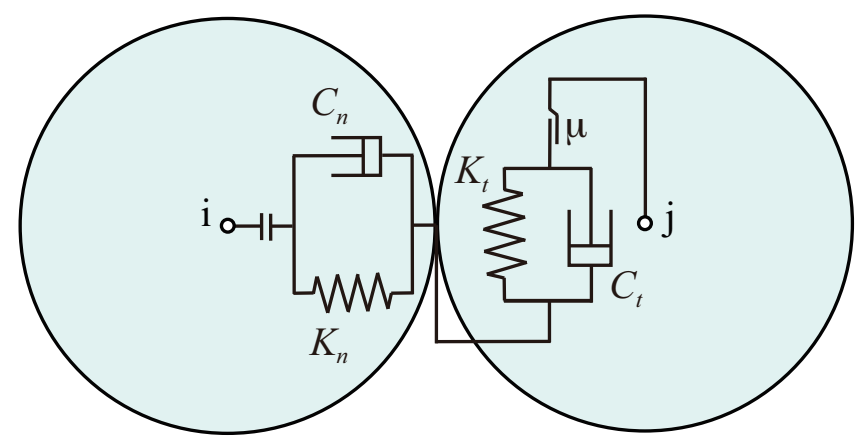

Figure 1: Contact model. 

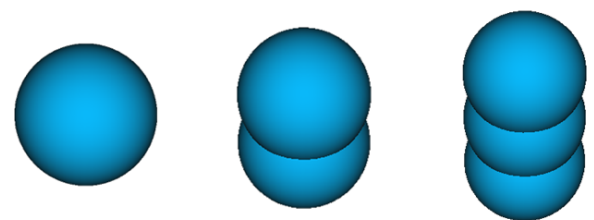

(1) S1

(2) L2

(3) L3

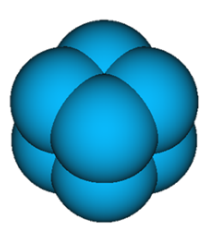

(4) $\mathrm{C} 8$
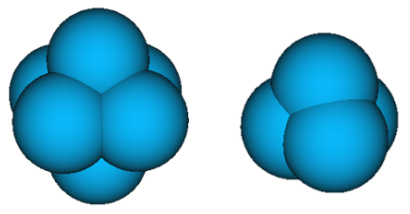

(5) M7

(6) T4

Figure 2: Elemental shapes in DEM. 


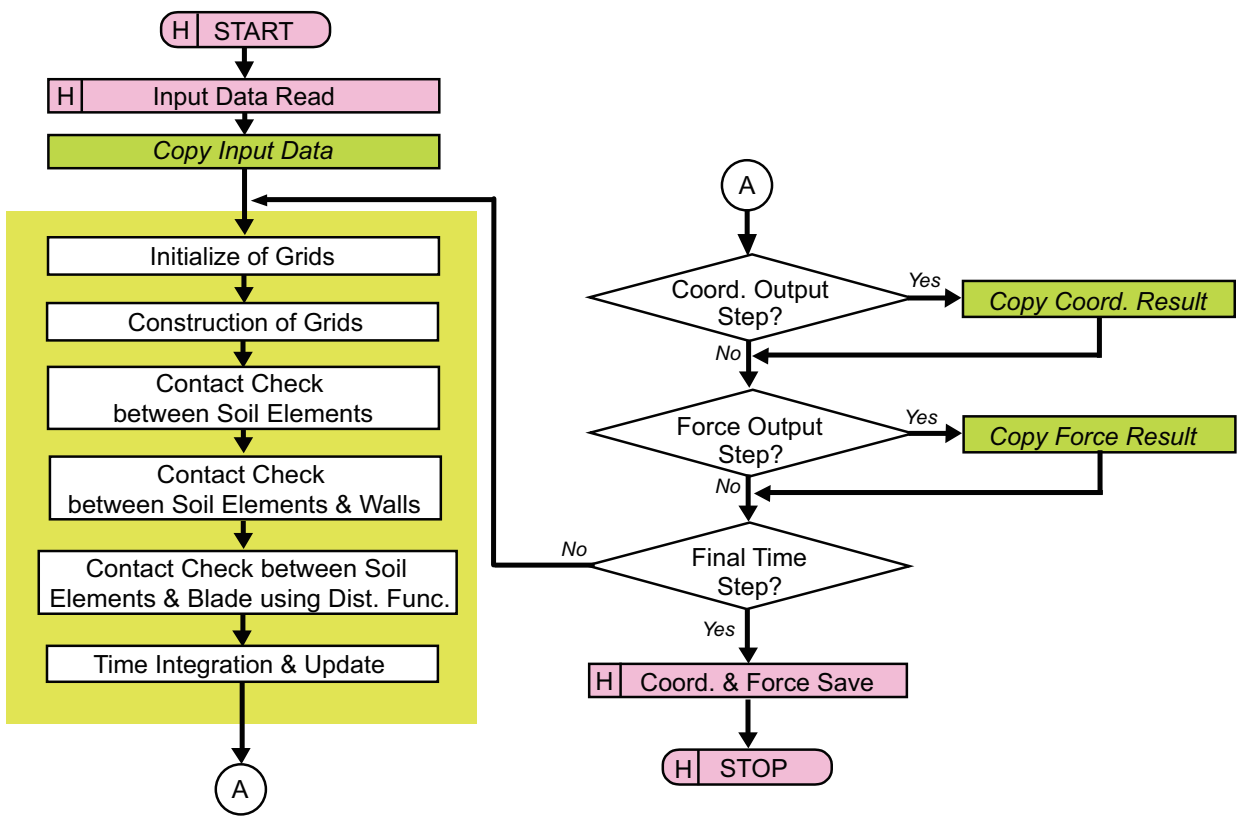

Figure 3: Schematic flow of DEM in GPU computation. 


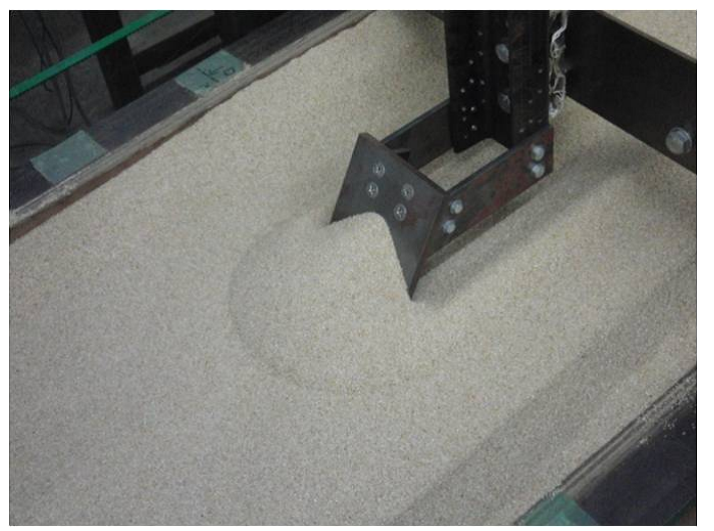

Figure 4: Photograph of a soil-cutting experiment. 


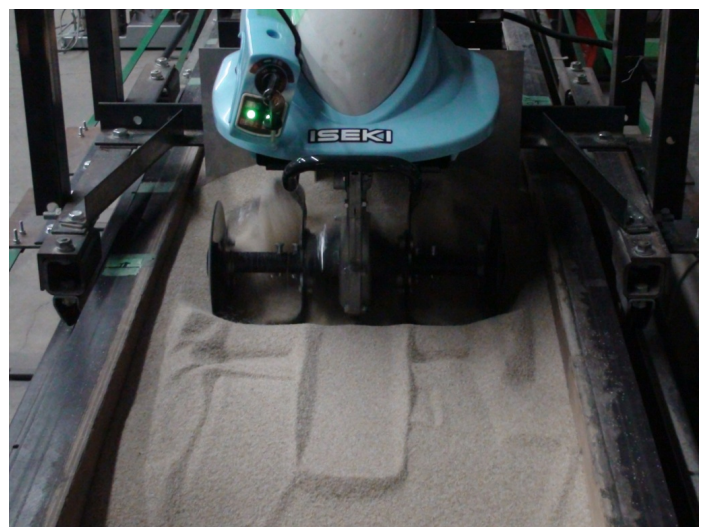

Figure 5: Soil mixing process using the electric rotary tiller in MCD. 


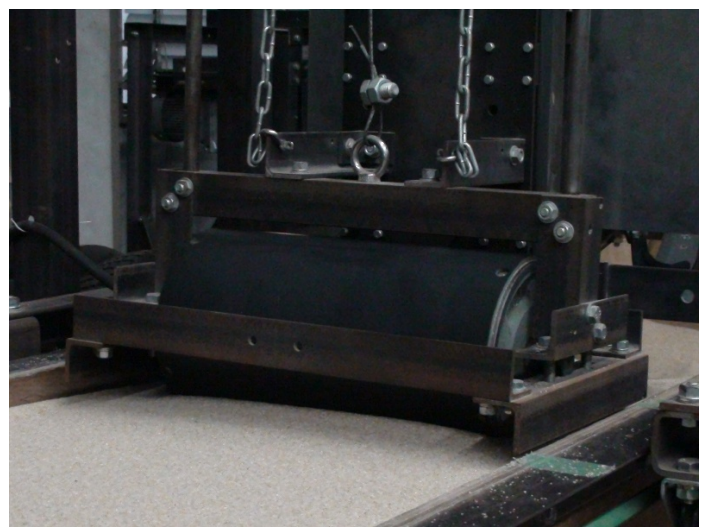

Figure 6: Soil compaction using a powered roller in MCD. 


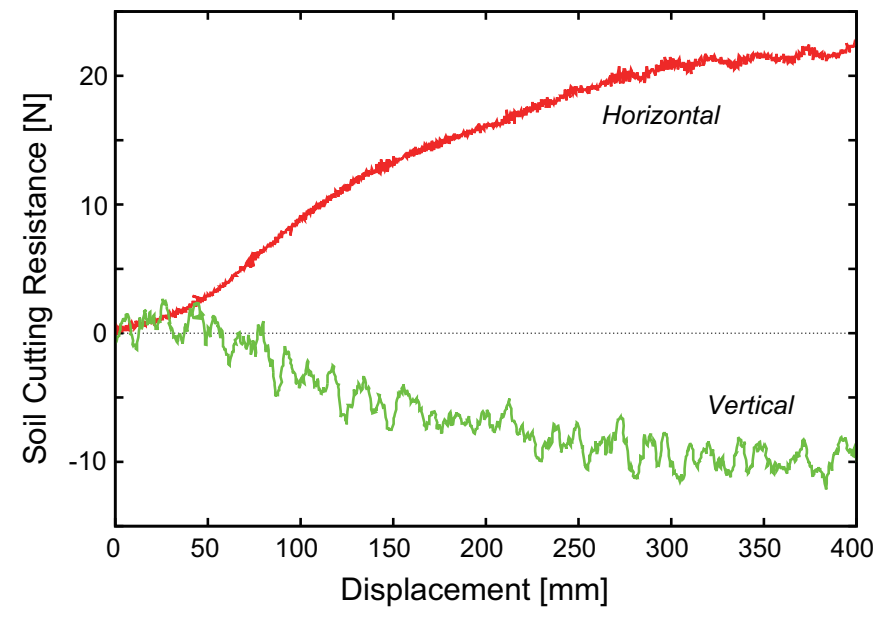

Figure 7: Example of an experimentally obtained results. 


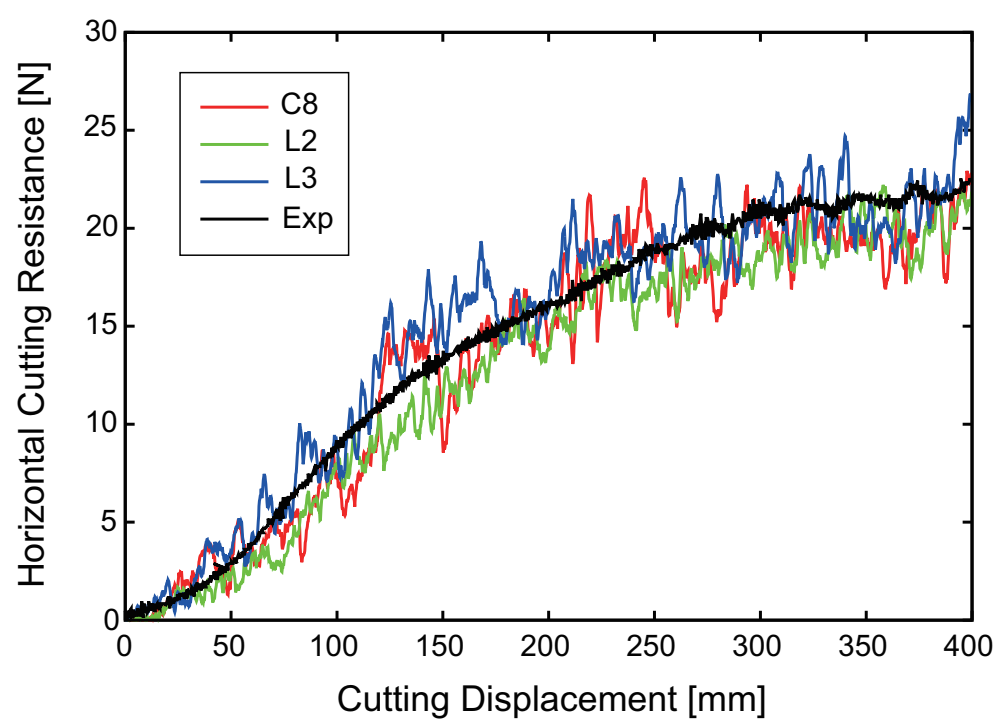

(a) Cases of C8, L2, and L3

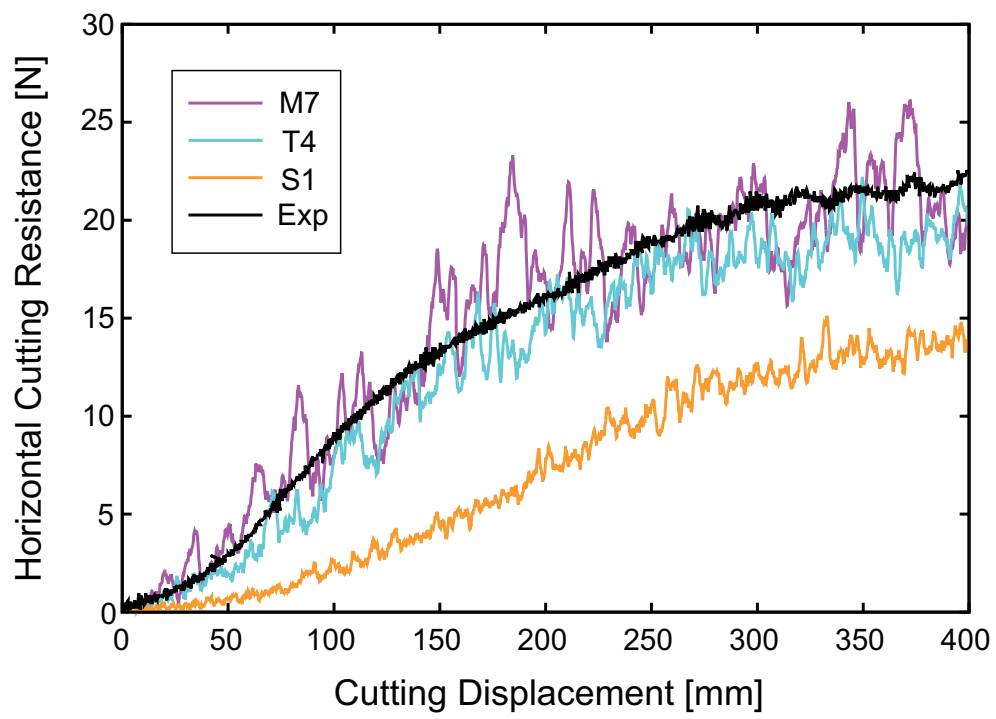

(b) Cases of M7, T4, and S1

Figure 8: Horizontal cutting resistance using MSM. 


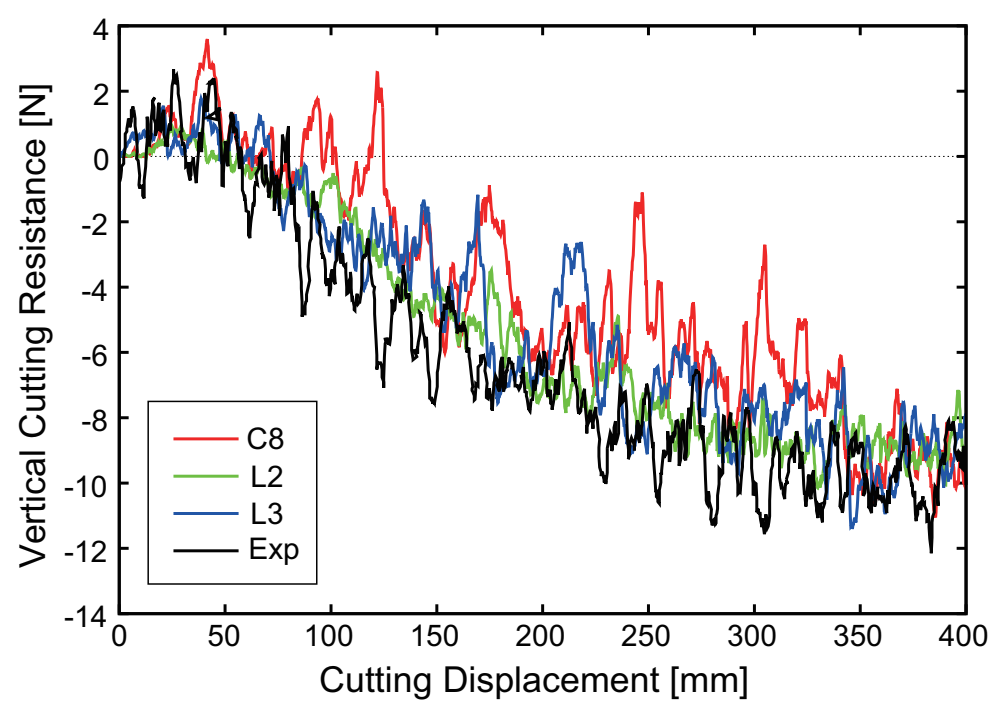

(a) Cases of C8, L2, and L3

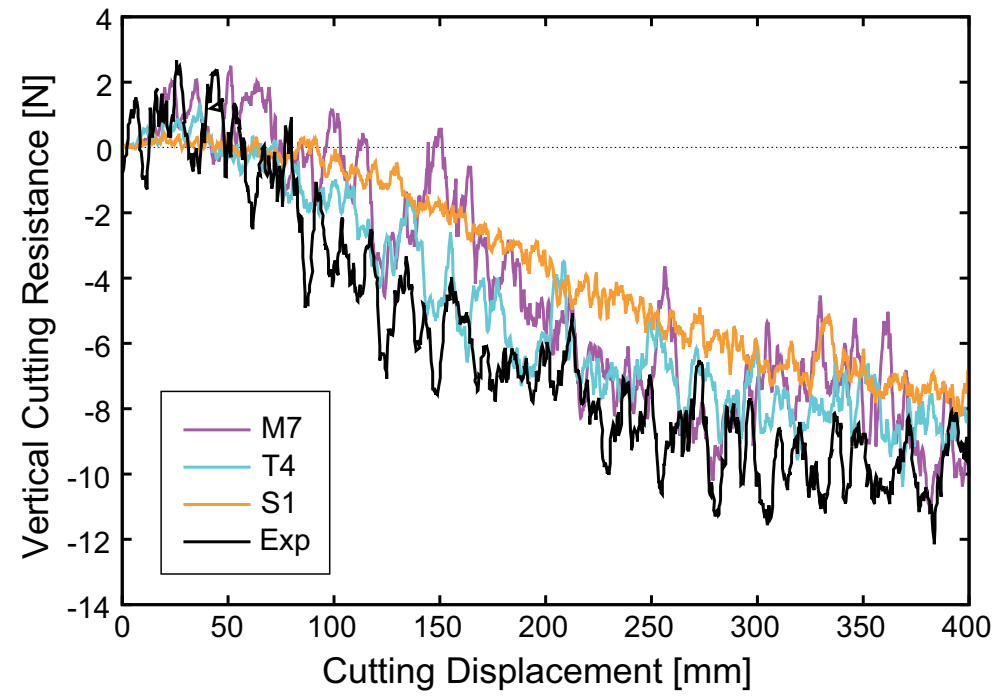

(b) Cases of M7, T4, and S1

Figure 9: Vertical cutting resistance using MSM. 


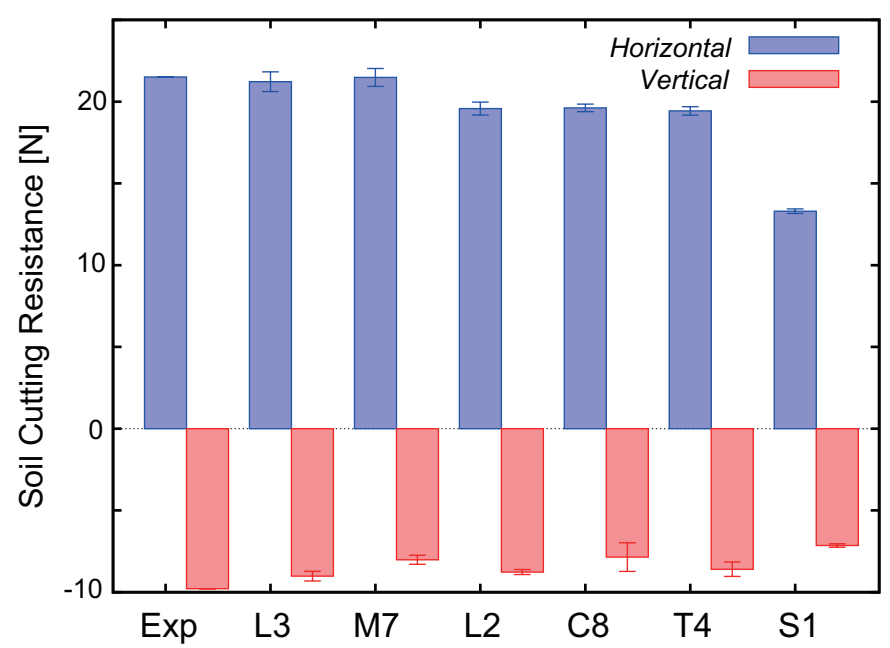

Figure 10: Comparison of average cutting resistance. 


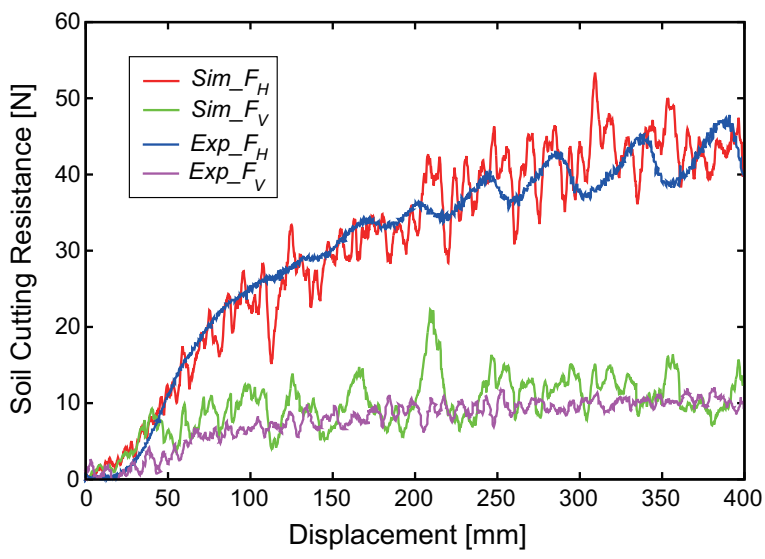

Figure 11: Case of 90 deg cutting angle. 


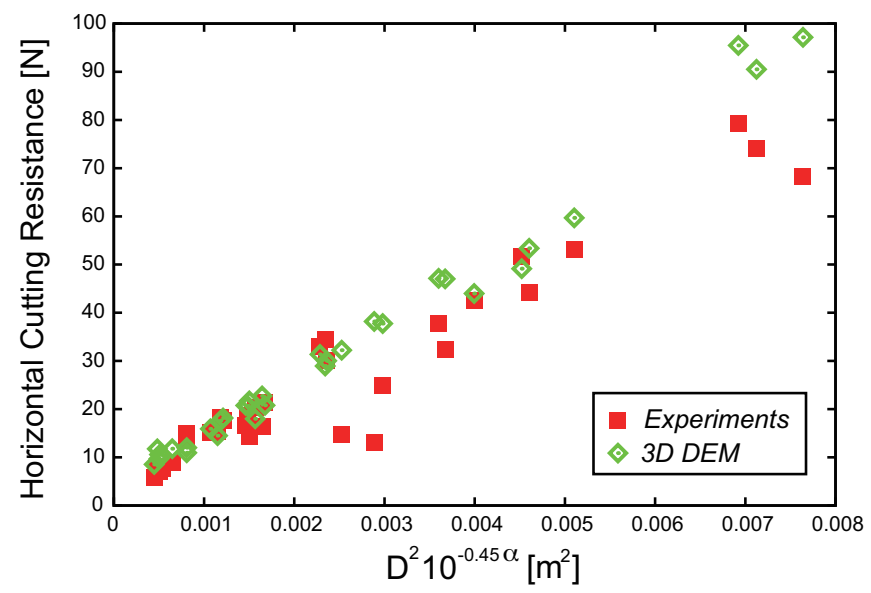

Figure 12: Horizontal soil resistance. 


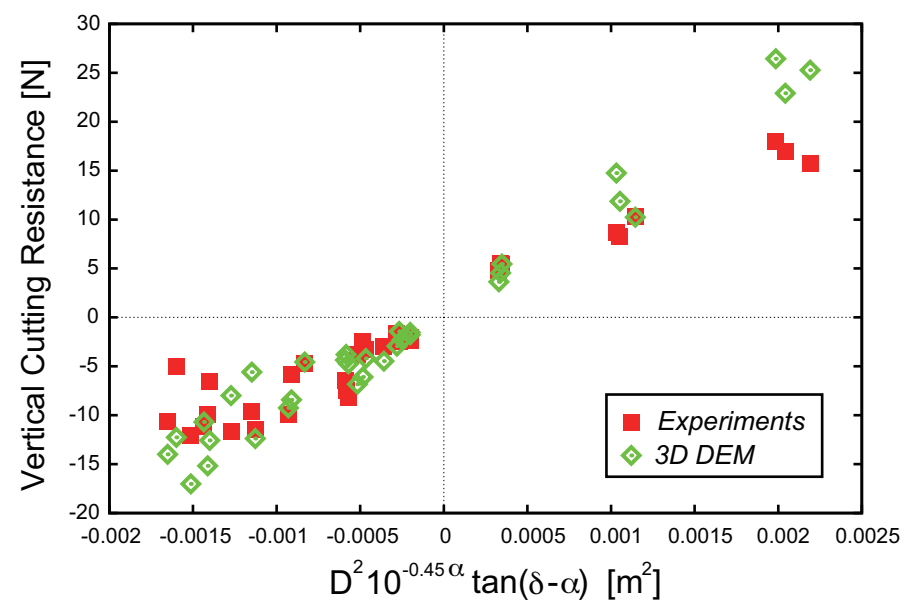

Figure 13: Vertical soil resistance. 


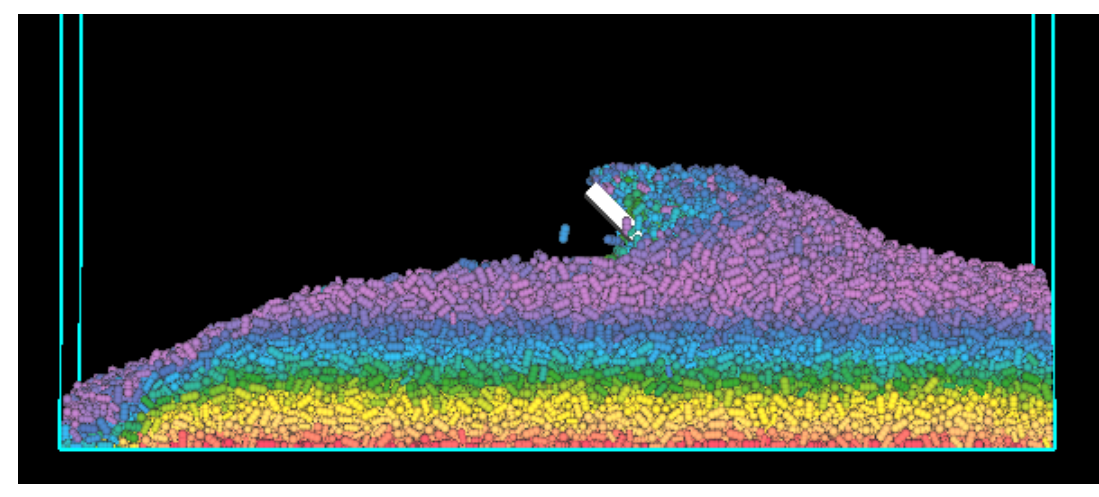

Figure 14: Side view of soil behaviors in L3. 


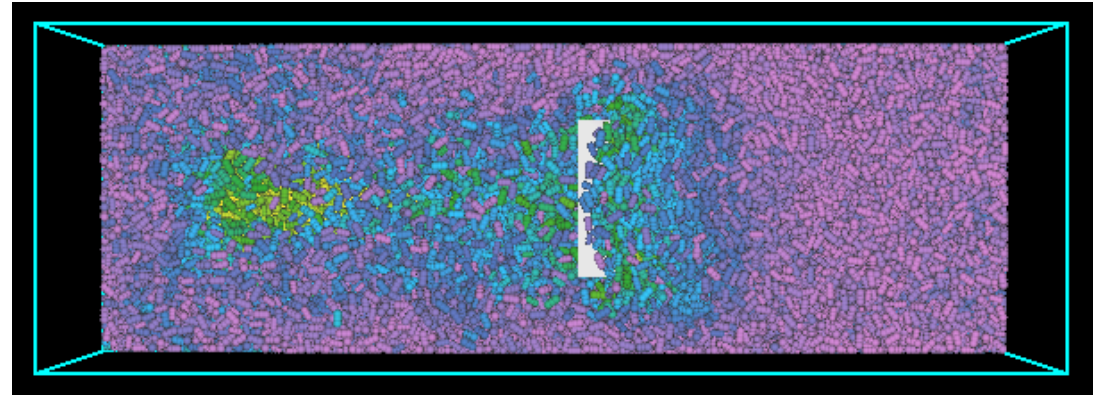

Figure 15: Top view of soil behaviors in L3. 


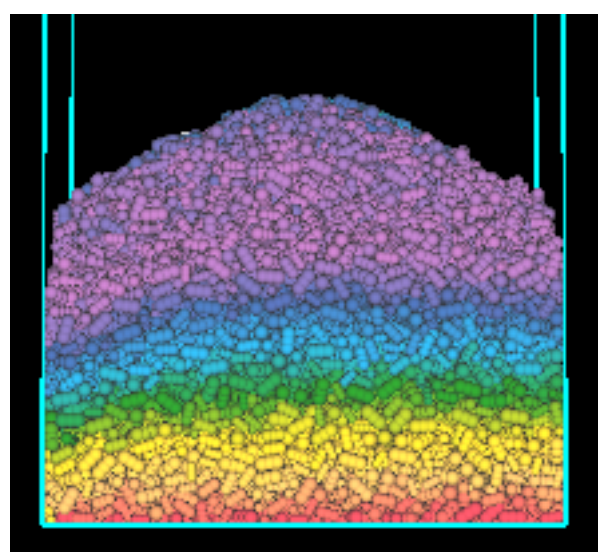

Figure 16: Front view of soil behaviors in L3. 


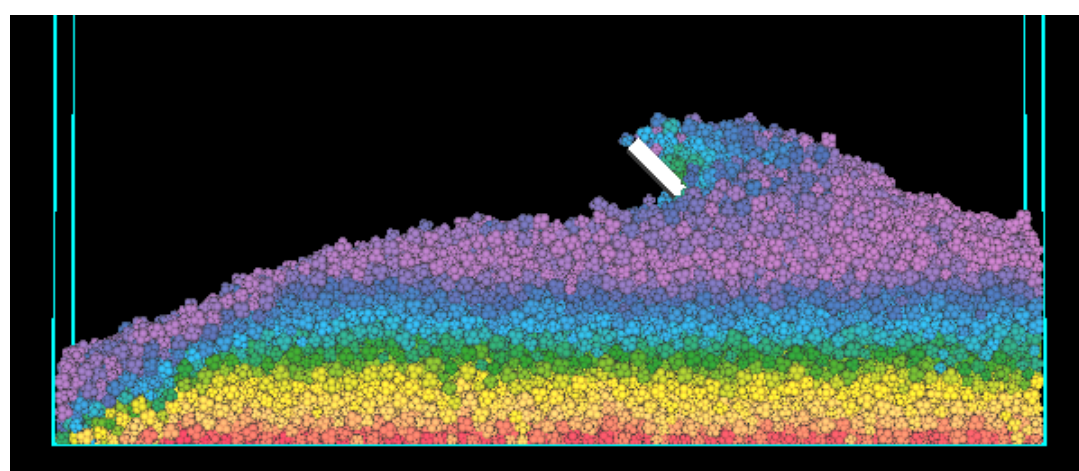

Figure 17: Side view of soil behaviors in M7. 


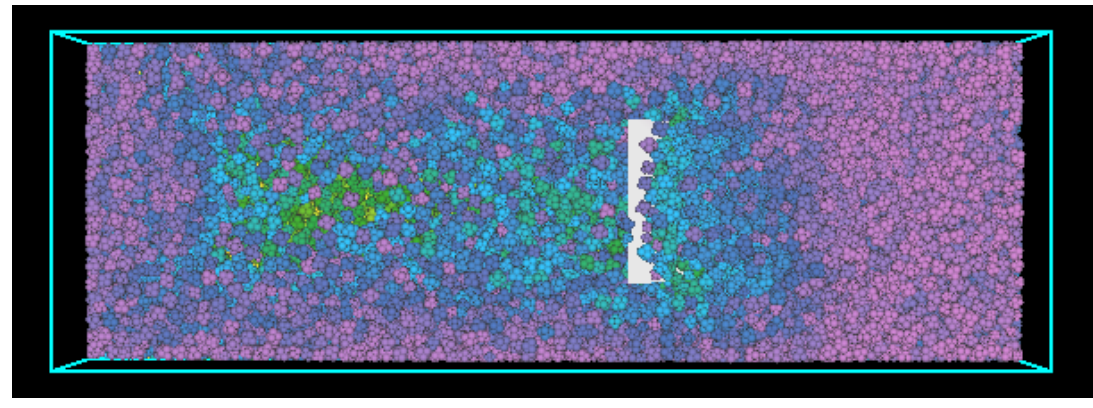

Figure 18: Top view of soil behaviors in M7. 


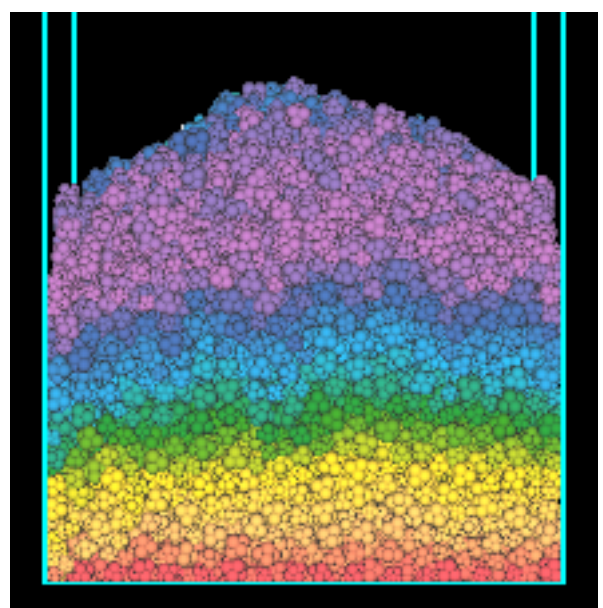

Figure 19: Front view of soil behaviors in M7. 


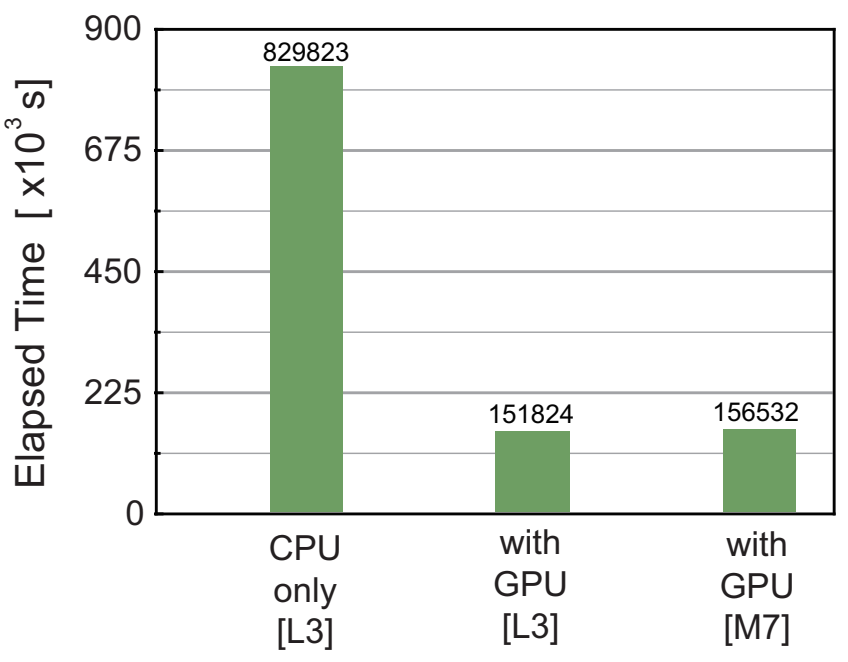

Figure 20: Elapsed time of 3D DEM using L3 and M7 models. 


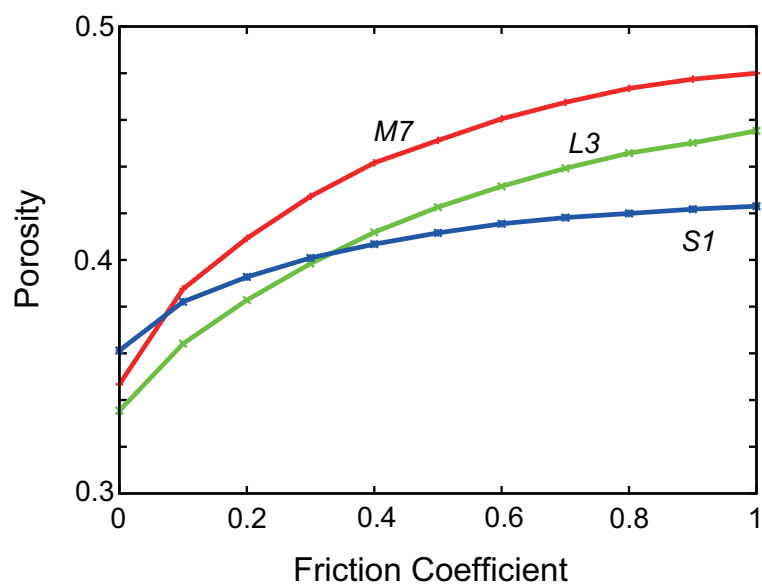

Figure 21: Possible porosity condition in DEM. 


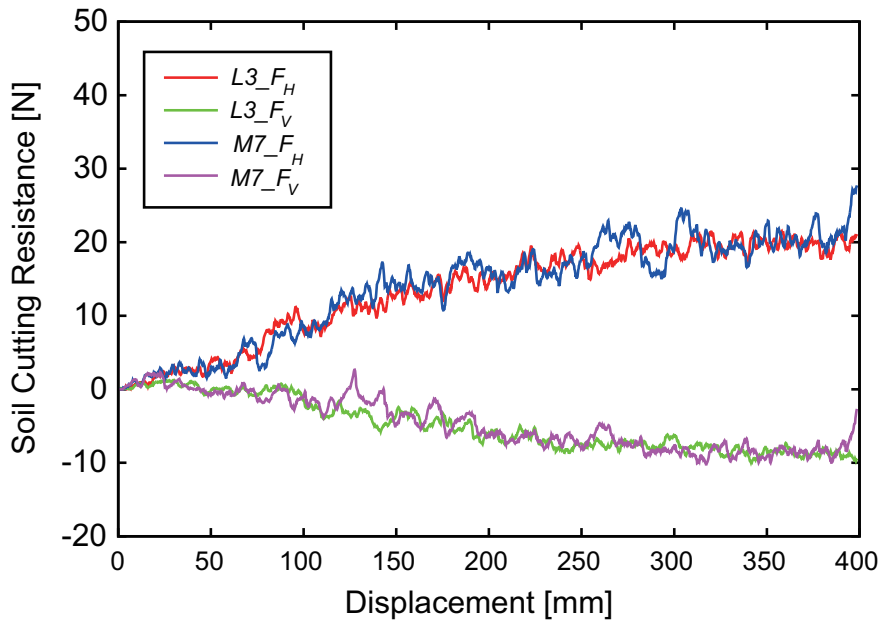

Figure 22: Case of porosity condition of 0.453 (H0). 


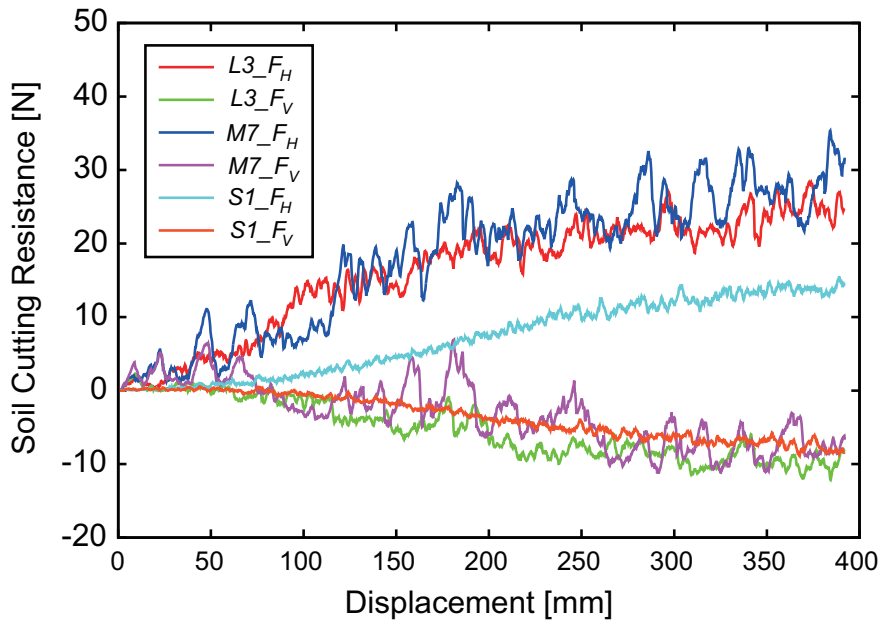

Figure 23: Case of porosity condition of 0.408 (H25). 


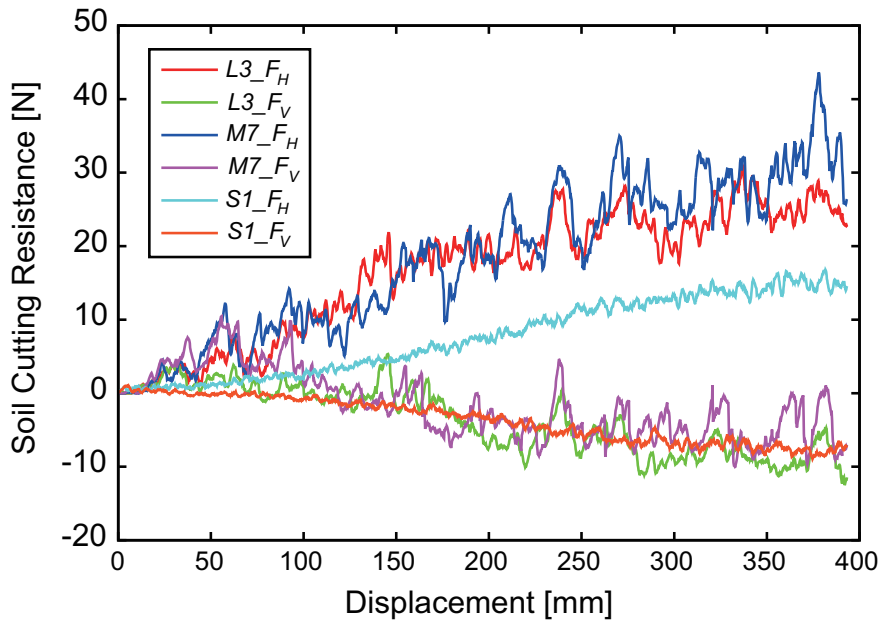

Figure 24: Case of porosity condition of 0.389 (H250). 


\section{List of Tables}

1 Contact parameters in DEM. . . . . . . . . . . . . . 54

2 Total number of particles in an MSM. . . . . . . . . . . 55

3 Combination of cutting depths. . . . . . . . . . . . 56

4 Normal and tangential cutting resistance, resultant, and friction coefficient. . . . . . . . . . . . . 57

5 Designed porosity condition in 3D DEM. . . . . . . . . . . 58

6 Average cutting resistances, resultant and friction coefficient for L3 model. . . . . . . . . . . . . . . . . . . . . 59

7 Average cutting resistances, resultant and friction coefficient for M7 model. . . . . . . . . . . . . . . . . . . . . . 60

8 Average cutting resistances, resultant and friction coefficient for S1 model. . . . . . . . . . . . . . . . . . 61 
Table 1: Contact parameters in DEM.

\begin{tabular}{cccc}
\hline Contact & P-P & P-W & P-B \\
\hline$K_{n}[\mathrm{~N} / \mathrm{m}]$ & 2000 & 2000 & 2000 \\
$K_{t}[\mathrm{~N} / \mathrm{m}]$ & 500 & 500 & 500 \\
$\mu$ & 0.56 & 0.56 & 0.3 \\
$e$ & 0.3 & 0.3 & 0.3 \\
\hline
\end{tabular}


Table 2: Total number of particles in an MSM.

\begin{tabular}{cccc}
\hline Model & NE & PN & NE1 \\
\hline S1 & 191994 & 1 & 191994 \\
L2 & 166056 & 2 & 83028 \\
L3 & 117363 & 3 & 39121 \\
C8 & 219776 & 8 & 27472 \\
M7 & 156016 & 7 & 22288 \\
T4 & 174480 & 4 & 43620 \\
\hline
\end{tabular}


Table 3: Combination of cutting depths.

\begin{tabular}{cccc}
\hline Cutting angle & \multicolumn{3}{c}{ Level of cutting depth } \\
$\beta$ [deg] & shallow & intermediate & deep \\
\hline 30 & $\checkmark$ & $\checkmark$ & NA \\
45 & $\checkmark$ & $\checkmark$ & $\checkmark$ \\
60 & $\checkmark$ & $\checkmark$ & $\checkmark$ \\
90 & $\checkmark$ & $\checkmark$ & $\checkmark$ \\
\hline
\end{tabular}


Table 4: Normal and tangential cutting resistance, resultant, and friction coefficient.

\begin{tabular}{ccccc}
\hline $\begin{array}{c}\text { MSM } \\
\text { Model }\end{array}$ & $\begin{array}{c}F_{n} \\
{[\mathrm{~N}]}\end{array}$ & $\begin{array}{c}F_{t} \\
{[\mathrm{~N}]}\end{array}$ & $\begin{array}{c}R \\
{[\mathrm{~N}]}\end{array}$ & $\begin{array}{c}\mu_{f} \\
{[-]}\end{array}$ \\
\hline (Exp) & 22.13 & 8.29 & 23.63 & 0.375 \\
\hline L3 & 21.38 & 8.62 & 23.05 & 0.403 \\
M7 & 20.86 & 9.52 & 22.93 & 0.457 \\
L2 & 20.04 & 7.64 & 21.45 & 0.381 \\
C8 & 19.42 & 8.32 & 21.13 & 0.428 \\
T4 & 19.82 & 7.66 & 21.25 & 0.387 \\
S1 & 14.46 & 4.35 & 15.10 & 0.301 \\
\hline
\end{tabular}


Table 5: Designed porosity condition in 3D DEM.

\begin{tabular}{ccccc}
\hline Condition & Porosity & L3 & M7 & S1 \\
\hline H0 & 0.453 & 0.453 & 0.454 & NA \\
H25 & 0.408 & 0.408 & 0.407 & 0.408 \\
H250 & 0.389 & 0.389 & 0.389 & 0.389 \\
\hline
\end{tabular}


Table 6: Average cutting resistances, resultant and friction coefficient for L3 model.

\begin{tabular}{ccccc}
\hline $\begin{array}{c}\text { Porosity } \\
\text { Condition }\end{array}$ & $F_{n}$ & $F_{t}$ & $R$ & $\mu_{f}$ \\
{$[\mathrm{~N}]$} & {$[\mathrm{N}]$} & {$[\mathrm{N}]$} & {$[-]$} \\
\hline H0 & 20.20 & 7.77 & 21.64 & 0.385 \\
H25 & 24.10 & 10.67 & 26.36 & 0.443 \\
H250 & 24.60 & 11.95 & 27.34 & 0.486 \\
\hline
\end{tabular}


Table 7: Average cutting resistances, resultant and friction coefficient for M7 model.

\begin{tabular}{ccccc}
\hline $\begin{array}{c}\text { Porosity } \\
\text { Condition }\end{array}$ & $\begin{array}{c}F_{n} \\
{[\mathrm{~N}]}\end{array}$ & $\begin{array}{c}F_{t} \\
{[\mathrm{~N}]}\end{array}$ & $\begin{array}{c}R \\
{[\mathrm{~N}]}\end{array}$ & $\begin{array}{c}\mu_{f} \\
{[-]}\end{array}$ \\
\hline $\mathrm{H} 0$ & 20.63 & 8.94 & 22.49 & 0.433 \\
$\mathrm{H} 25$ & 25.14 & 14.77 & 29.15 & 0.588 \\
$\mathrm{H} 250$ & 25.59 & 18.36 & 31.50 & 0.718 \\
\hline
\end{tabular}


Table 8: Average cutting resistances, resultant and friction coefficient for S1 model.

\begin{tabular}{ccccc}
\hline $\begin{array}{c}\text { Porosity } \\
\text { Condition }\end{array}$ & $F_{n}$ & $F_{t}$ & $R$ & $\mu_{f}$ \\
\hline $\mathrm{N}]$ & {$[\mathrm{N}]$} & {$[\mathrm{N}]$} & {$[-]$} \\
\hline $\mathrm{H} 25$ & 15.79 & 4.09 & 16.31 & 0.259 \\
\hline
\end{tabular}

